\title{
3. Energy as domestic power: the case of Gazifikatsiya Rossii
}

This chapter is based on my interest in major Russian fossil energy companies as an instrument for promoting a wide plethora of state-led objectives, encompassing societal phenomena from economy to politics and from culture to identity. I focus on how hydrocarbon energies, specifically gas, as it is so central within Russia, are intertwined with societal and political power - and how the materialities and spatialities of hydrocarbons are utilized in constructing and maintaining power in the Russian domestic context.

\section{STATE PRIORITIES IN GAZPROM'S CORPORATE GOVERNMENTALITY STRATEGIES}

Gazprom is the successor of the Soviet Ministry of Gas Industry, and it has been an open joint-stock company since 2005, with the Russian state owning the majority of shares (50 per cent plus one stock). Modern-day Gazprom has more than 450000 employees and, in addition to the energy sector, it is active in finance and media (Gazprom 2015e). Although it is technically a commercial enterprise, given its strong relationship with the Russian government, Gazprom can be defined as a 'parastatal company' (versus a completely state-controlled corporation, such as the nuclear giant Rosatom). As a parastatal company, Gazprom is subject to the authority and decisions of the Russian state and President Putin's entourage - far more than its corporate legal status would suggest. All major strategic choices, operations abroad, large infrastructure decisions and national programmes, such as the Gazifikatsiya programme and other corporate social responsibility operations, are made with the blessing of Putin and his peers. This is not to suggest that decision-making in the company is entirely politically motivated: its executives exhibit clear evidence that a business rationale is the main motivation for operational decisions taken by the company (Kivinen 2012). Moreover, Gazprom is a vast company with dozens of regional subsidiaries - each with differing objectives and political voices - operating in the Russian provinces and 
internationally (Gazprom 2015b). Overall, however, when analysing the corporate governmentality practices of Gazprom, we are dealing with a parastatal company that is steered by the country's elite and therefore enjoys privileges in the Russian economic and political context that are unseen by any other company.

Gazprom's position in the Russian domestic energy sector is therefore exceptional. However, in the 2010s, Gazprom lost its monopoly, legally speaking, over gas exports and control of the domestic gas pipeline system. Other gas producers, such as the private gas firm Novatek as well as oil companies, now have the right to feed gas into the national system and to export it. Despite the fact that more competition is now tolerated, Gazprom's monopolistic practices prevail, which enables it to diminish competitors' chances to increase their share in regional energy markets (Tynkkynen 2014). Since the Russian energy scene cannot be further dominated by Gazprom, the company's decision-makers perceive a need to engage in branding or 'imago-promotion' activities, such as social responsibility programmes and infrastructure construction, in order to safeguard its position - both in the market and in the minds of Russian citizens. Perceiving the latter to be of increasing importance, Gazprom engages in a wide range of corporate social responsibility activities. Sponsoring sports, for example, has been one of the central means of enacting this agenda (Gazprom 2015a). In welfare societies, which the Soviet Union and its successor Russia purport to be, local and regional governments have traditionally been delegated the responsibility of developing communal infrastructures, including public sport and health facilities. Thus, in assuming responsibility for developing such facilities, Gazprom has been granted - and has itself taken on responsibilities - that are traditionally considered the tasks of the government. In the following, I will delve into how the Gazifikatsiya Rossii promotional video is understood as a specific energy- and geography-related governmentality and as a form of energopower within the hydrocarbon culture in the making in Putin's Russia.

\section{GAS'S PATRIOTIC, SACRAL AND GENDERED PATH FROM SOIL TO SOUL}

The aim of the video, as stated in the insert, is to show how the gas used in Russian kitchens is produced, refined and transported to end consumers. The story starts in the countryside of the Ivanovo region by claiming that "few of us think how the gas consumed in our stoves is produced" and what kind of journey that gas takes before arriving at 
people's homes. In a National Geographic documentary style, the video then follows the host, a young female reporter, as she visits sites along the path taken by the gas. When comparing the style chosen and the ethos promoted by the post-Soviet film scene, I see that the narrative of Gazifikatsiya Rossii is clinging to the popular patriotic genre, but not unequivocally dominating the scene at the time the video was produced, as described by Norris (2012). However, the nature of the video is very far from the nationalistic-patriotic pathos of many post-Soviet movies produced during the Putin era, and looks very professional in comparison to the many quasi-scientific documentaries abundant on Russian television during the previous decade. Moreover, the strategic nature of the promo video is visible also in the fact that it is free from the miniature fault lines that we see in Russian state television (cf. Hutchings and Tolz 2012).

The host interviews and talks to various people, including: healthy and physically-fit gas producers at production sites in the Yamal Peninsula during harsh winter conditions; engineers in clinically-clean compressor stations; suave and well-off directors at Gazprom's Moscow headquarters; well-equipped welders and excavators constructing artery and distribution pipelines; male heads of municipalities; and ordinary mothers in the picturesque Russian countryside, who are happy to receive gas. This advertising video ends by returning to the sites of gas delivery and consumption in the Ivanovo and Kaluga regions on a warm and sunny summer day.

I argue that the Kaluga and Ivanovo regions are chosen not by chance as end points in the video. They are the 'peripheral' regions closest to Moscow. As I learned, for example, from discussions on Russian social media, one focal point of criticism towards the state and Putin's regime is the fact that it has not been able to provide social amenities to Russians on an equal basis outside big cities (e.g. Bezperspektivnye ... 2014; Selo \#Fedorovka $200 \mathrm{~km}$ ot Moskvy ... 2016). Thus, the need to counter the impression that 200 kilometres from Moscow there is no gas and Russia is merely an 'energy-producing appendage' of the West fits in well with the choice of regions in this video (cf. Rutland 2015, p. 75). The choice is further justified because it helps tame public dissatisfaction towards the ruling elite and the chosen economic system that is increasingly dependent on the hydrocarbon sector (Gustafson 2012, p. 493). As Peter Rutland (2015, pp. 75-6) argues, despite the fact that the majority of Russians consider their country an energy superpower, most simultaneously oppose the wealth enjoyed by the elite and created by the energy trade, even as many Russians live in factual energy poverty. Therefore, one 
motivation to produce the video is the need to change this impression and fortify the position of Putin's regime.

The most obvious aim of the Gazifikatsiya promotional video is to convince the audience that gas is a reliable and truly Russian source of energy, while also showing that the extraction and delivery of gas to settlements and finally to consumers is a far from easy task. From the beginning of the video, the difficulties that must be overcome and the sacrifice that has to be made, both at a national and individual level, construct guilt that is placed on the (Russian) audience. An almost hallowed message is put forward throughout the video: Russians should not overlook the importance of gas for their society, nor should they overlook the difficulties that must be overcome to deliver gas from the extreme Northern environment to the Russian heartland. The words trudno (difficult) and tyazhelo (hard) are repeated throughout the video when gas exploration, production, and pipeline construction, both artery and distribution, are shown and discussed.

The journey to highlight the path of gas from the gas deposits to the consumers starts in the kitchen of a typical Russian single-family home in the countryside of the Ivanovo region, where tea water is boiling on a gas stove. The philosophical conclusion is that gas links Russians to the motherland and its geography: gas travels from "uninhabited" territories (Yamal) to the Russian ethnic and cultural heartland. Thus, gas as a commodity and the gas pipelines that transport it are a lifeline for Russians. The video uses both Soviet modernization and traditional orthodox history to persuade the spectator. The constructed narrative builds on the idea that the gas flows from the Russian soil and from the natural environment already tamed by Soviet society and its modernization efforts, as the work of Soviet geologist-explorers is underlined. Likewise, the final destination of the gas, a traditional Russian village with orthodox chapels forming the settlement's skyline and wooden houses painted in Russian blue, is located close to the core of Russia, the old Rus'.

Throughout the video, a distinctive normalization takes place: individuals and local and regional authorities who support the development of gas infrastructure are presented as true Russians through visual, sound and vocal hints. People and communities who oppose this development are presented as abnormal. The video makes clear that people and communities who refuse to request or accept gas as a source of energy are responsible for keeping Russia in a pre-modern condition, with a poor national economy and harsh everyday living standards for the people. A wide nationalistic-geographical imagery spectrum is utilized as gas travels and, along its path, links the geology, economy, culture, and even 
theology of Russia. Religious phrases are not utilized, but through chosen images and sceneries the narrative argues that Russian gas is flowing from the Russian soil to the Russian soul.

The literature focusing on the societal effects of hydrocarbons underlines the specific materialities and spatialities of these energy resources, coupled with the dominance of this sector in the national economy especially in Russia, and it promotes an understanding of geographical space as the controllable flow of resources, not as a territory of communities (e.g. Bridge 2009, 2010, 2011; Watts 2004a, 2004b). Referring to concepts used by Manuel Castells (1999), hydrocarbon commodity chains have agency and accentuate spaces of (controllable) flows over spaces of (lived) places. This understanding of geographical space seems to have been taken into account, or at least there are hints that the producers of the Gazifikatsiya video are aware of it. The identity of the individual gas consumers, or the settlements attached to the gas distribution system, are constructed using a distinctive 'sense of place' that derives its power from the material characteristics of the gas itself, as well as from the ability of the gas infrastructure to connect people, settlements and the nation. The gas flows from the Russian soil to the Russian soul by producing a sense of Russian place. That place, however, is ultimately placeless as the multiple localities of the gas nation are represented as identical by images, maps and discourses. This placeless image of Russia fits in well with one of the main objectives of President Putin's regime - to view Russian territory as culturally and economically homogeneous in order to suppress regional identities and avoid separatist sentiments (cf. Laruelle 2014a, pp.7-9; Warhola and Lehning 2007, p. 934).

This ethno-culturally coloured plea to the audience is accentuated by choices about how to define gender roles. All the experts and directors interviewed in the video that have something to do with gas production, transport, pressurizing and control are male. The only females in the video are the female reporter, who is escorted to a male-dominated world of gas, thus producing a kind of father-daughter relationship; the doctor who takes care of the health and well-being of the gas workers in the harsh Arctic environment; the mothers interviewed as gas has reached their village and homes; and the young girls who have a special role in the village festivities when the gas is lit for the first time. Thus, gas relies on and fortifies conservative Russian values. The suffering of men caused by a harsh and isolated life at remote production platforms and pipeline construction sites is compensated for by the fact that men are in control and occupy positions of power. Women are controlled and fall under the patronage of men, the company, and the state, but have some power in their role as healers, consumers, and producers of new generations of 
Russians. These gendered roles date partly from Soviet practices and culture. Women are viewed also as highly educated professionals, but simultaneously as mothers and 'beauty queens', whereas men are presented either as executive bosses or as heroic and masculine industrial workers. They also clearly go hand-in-hand, however, with the contemporary conservative turn in Russian society and politics. According to Makarychev (2013, p. 247) the Russian leadership has argued that Russia is "the bastion of the conservative world". It is no surprise that parastatal Gazprom and the gas industry are viewed as guarantors of this Russian mix of neo-conservative and traditional patriarchal values. Clearly, gas is a strongly gendered substance and helps to build and maintain a specific form of geo-governmentality.

The constructed narrative clearly plays with national geographic categories. My analysis of the video reveals the construction blocks of Gazprom's geo-governmentality. Gas as a resource - its spatialities and the materialities (gas geology, gas networks, hubs, arteries, distribution lines and connectedness) along with direct (warmth and energy security) and indirect considerations (modernization, economic growth, promise of patronage and traditional values) and the 'work' of gas - comes across in the governmentality of a powerful Russian enterprise. In a similar manner as Watts (2004b, pp. 53-4) describes in his study on Nigeria, I find how the formation of governmentality is constructed on the different meanings assigned to hydrocarbon resources. The question I pose follows the logic of Huxley (2007, p. 194; see also Whatmore 2003, pp. 26, 33). That is, as she urges us to ask anew in the geographical context at hand, how do specific resources or spaces act as agents as part of the discursive-practical use of power, or of governmentality? This 'agency' of space and the materialities it holds link the geo-governmentality approach to Latour and his actor-network theory to the wider discussions in science-technology studies about the role of the material and the technological in human life, culture and politics.

The video shows how the different dimensions of governmentality and geography come together. Similarly, Legg (2005, pp. 147-9) furthers Dean's power-truth-identity nexus described above, and operationalizes geographically informed governmentality analytics by naming five "dimensions to regimes of government": specific ways of thinking, understanding reality, constructing subjectivities (and refuting others), strategic technologies of rule, and the values of a specific government. The thinking, understanding of reality and values at Gazprom are linked to those constructed subjectivities that are visible in the video: the strategic technology of rule. Moreover, these different dimensions of governmentality were approached by studying one programme of rule 
that, as Legg (2005, pp. 145-6) has pointed out, can function on several scales: as a single subject, as a territory, as a nation, as a population, and globally. In these dimensions and scales of governmentality, geography (space, territories, the environment, resources, technologies and infrastructure) does play a role, and I am able to unfold these links and roles by studying Gazprom's gas distribution programme as presented in the promotional video. Thus, I understand the Gazifikatsiya video here both as a representation of a specific programme of rule (the Gazifikatsiya programme) and as research material enabling us to look at the thinking, rationalities, values and actions of a 'government' - a parastatal energy company - vested with significant power in the Russian political context. As described above, the power-vested discourses and practices linked to Gazifikatsiya utilize the whole repertoire of Legg's scales - tying the personal to the national and the global territories - to amalgamate geography with the practised governmentality.

\section{BIOPOLITICAL OBJECTIVES TIED TO GAS}

The message put forward in the video is aimed not only at specific subjectification, but also at producing new responsibilities that have traditionally been considered the duty of the state. The duty of every Russian is to take part in the national enterprise to construct a nationwide gas system. Thus, a national-level objective is turned into a personal task. Russians, from mothers to the heads of municipalities, are persuaded to take a central biopolitical problem posed at the level of the Russian state - the provision of energy and heating for the population - as their personal problem. The video implies that if we (Russians) do not think positively about gas and 'invite' it into our village, we betray our countrymen and stand in the way of others' well-being. Indoor temperatures are explicitly mentioned as a problem, and gas is a solution to it. Moreover, low indoor temperature is problematized by linking it to the health of children, Russia's future generations. Unsurprisingly for a gas commercial, sources of energy that could be promising in some regions, such as bioenergy and/or coal, are presented as the source of the problems gas is trying to solve. Therefore, these local and regional energy sources are demonized due to the negative societal effects they allegedly produce.

This narrative plays very cunningly on the topic of scarcity. In the Russian context, the question of 'scarcity' of gas is not only related to basic needs, but it also has a dimension related to national identity. This notion of gas scarcity is intertwined with similar national ideals and 
expectations. The Russian national identity is increasingly constructed in a manner that links Russia's hydrocarbon abundance to Russia's societal modernization and the Great Power aspirations that this energy abundance both enables and legitimizes (Bouzarovski and Bassin 2011, pp. 784, 787-8). The core appeal of Gazifikatsiya rests in its ability to do away with several dimensions of scarcity, which is especially appealing to those generations of Russians who have experienced the shortage economy of the 1980s (Kornai 1980). The video is trying to convince the audience that by connecting to the national gas distribution network, energy security is no longer an issue and Moscow has noticed your home, community and region and the federal centre will look after you. This resonates well with Collier's (2011, pp. 212-14) argument that indoor temperature is a central biopolitical (domestic security) problem posed for the Russian state and governing regime. This, again, can partly be explained by the persistent Soviet legacy - there is a shared understanding among Russians that heat and even power should be provided by the state free of charge or, at least, inexpensively (Collier 2011, p. 239).

The narrative found in the video combines patronage and (bio)security in such a manner that it resonates well with the concept of energopower (Boyer 2014, pp. 321-8; Rogers 2014, p. 436). Thus, governmental concern over energy supplies is associated with both the biopolitical aims of guaranteeing the (bio)security of the population as well as the exertion of control over populations and the production of economic accumulation by keeping energy flowing in grids and pipelines. Energopower can serve as an analytical tool that helps people understand how power and the materialities of energy are intertwined. The energopower approach explicitly reminds us of the binary nature of contemporary energy systems in their ability to do both 'good' and 'bad'; that is, energy systems are a means of delivering amenities and controlling the population. In the Gazifikatsiya video, this binary connotation is immanent - Gazprom delivers, along with its pipelines, (bio)security for individuals and communities, and also the feeling that the state is able to control from afar.

\section{GAS (INDUSTRY) AS A GUARANTOR OF RUSSIA'S MODERNIZATION}

One central argument in the video is that the gas industry is modernizing Russia. Gazprom is viewed not only as a guarantor of Russia's technological and economic modernization, but also as a social guarantor. 
The technology utilized in the gas industry is referred to as kosmicheskaya tekhnologiya (space technology), which has been developed in Russia due to the extremely demanding environmental conditions in which the gas industry is forced to operate and the high standard of science and engineering that has been developed to overcome this natural limitation. Again, the geo is part of the modernization narrative and functions as the cornerstone of governmentality. Furthermore, the way in which the gas industry is viewed socially clearly bridges the gap between professions and 'classes'. This is not a new idea, as during the Soviet Union period different industrial branches developed distinct identities; for example, gas workers identified themselves as gazoviki and oilmen as neftyaniki, regardless of rank. Hence, when in the video the directors of Gazprom claim to "know the pipeline welders by name", this feeling of togetherness is utilized to produce an understanding of the gas industry as a safeguard of the national social contract, basically arguing that Russia's current societal modernization obtains its essence from Soviet egalitarian discourse.

The implicit message of this picture of the gas industry's role in economic modernization hints that a prominent objective of Dmitrii Medvedev's presidency, economic diversification away from the dominance of the energy sector, has been abandoned (Gustafson 2012, pp. 490492). The video argues that the multibillion rouble investment into Russia's gas industry has turned this branch into "the locomotive of Russia's economy". For Gazprom as a commercial company, this kind of reasoning is understandable. Still, Gazprom has to be viewed as also reflecting the state's rationalities: diversification is no longer pursued with the same vigour as before, which concurs with Gustafson's argument that in the eyes of Vladimir Putin and Igor Sechin, the hydrocarbon sector is and will remain the undisputed locomotive of the Russian economy (Gustafson 2012, p. 493).

Despite the single possible usage of carbon-based fossil energy, the modernization of Russia via gas is defined as something with no end in sight. This argument is supported in the video by references to the reserves of gas as ogromnye zapasy (enormous reserves) and samye krupnye mestorozhdeniya na planete (the planet's largest deposits), as well as by repeating numbers (trillion cubic metres and for decades to come), thus giving the impression that modernization based on gas will continue for an unlimited period. This speech derives its core from, once again, Soviet or even tsarist-era discourse: natural resources are an unlimited cornucopia for the nation (Fryer 2000). Here again, geographical imageries and scales - endless, globally vital recourses - form the basis of this modernization narrative and governmentality. 
The gas industry is presented as a modernizing agent in peripheral Russia, both upstream and downstream. Gas infrastructure not only provides warmth and well-being for peripheral communities where gas is delivered, but brings 'civilization' to the extreme North, as well. The gas production infrastructure enables the societal and economic development of the "uninhabited" northern production territories. A significant share of the video is devoted to describing how transport infrastructure (roads, airports) built for the gas industry promotes economic opportunities in these regions. In addition, 'civilization' is transplanted to the Yamal North as gas workers are taken care of in a scientific and precise way, including a daily physical examination (by the female doctors), while the workers' diet and working hours are adjusted for the requirements of a northern environment. Gazprom and Gazifikatsiya are viewed as central actors promoting regional development - modernization and civilization - involving both the peripheries of production and centres of consumption. The viewer is assured that by buying into this gas strategy, one promotes these objectives on a national scale. Gas and the Gazifikatsiya governmentality thus tie the individual to both Russia's physical and economic geography.

\section{PIPELINE AS CONTROL TOOL AND MODERN WARFARE}

The Gazprom video argues that local and regional authorities are not fulfilling their obligations in constructing gas infrastructure in the settlements. According to the Gazifikatsiya programme, the obligation of Gazprom is to deliver gas "to the municipality's border" while the local authorities' task is to build a local gas distribution network. Gazprom is working to encourage local populations to pressure district and region leaders to prioritize working with Gazprom on Gazifikatsiya projects. The obligation to take part in and promote national biopolitical goals by focusing, for example, on indoor temperature and children's health has another dimension to it: Russians are not only gently enticed (discursively) to take part in this national endeavour but also urged to succumb to the patronage of the parastatal company. The promise to deliver patronage and the claim to submit to it is exemplified by the way the arrival of gas to a peripheral locality is organized and shown in the video. First, Russians are made to believe that gas infrastructure extends everywhere, as even the most remote settlements are the focus of attention for the state and the company. Second, the video tries to assure 
all Russians that gas will arrive and link them with state-run infrastructure. The fact that the state 'arrives' together with the gas is exemplified in the video by the arrival of federal authorities and Gazprom officials at the villagers' house to cook food on gas stoves and to light up a fakel (flare) located in the village square. The message is that through a gas connection, villagers are connected to the company and the state, coming under their patronage and also under their control. What I see at play here, when viewed from the geo-governmentality and energopower perspectives, is a combination of both identity construction and disciplinary power made possible via the materialities of energy.

The geo-governmentality and energopower of Russian gas that I aim to unfold here dovetail well with theoretical contributions in the disciplines of political geography and ecology regarding the materialities of energy. I refer here to the work of Bakker and Bridge (2006; also Bridge 2009; Bridge 2010, pp. 527-8; Bridge 2011, pp. 316-20; Watts 2004a, pp. 200-202; Watts 2004b, pp. 75-6). The main contribution of this work has been the taxonomy of effects that the hydrocarbon sector has had on societal development via its spatialities and materialities. For example, the proposition that hydrocarbon industries produce a specific chokepoint geography - in other words, the agency of narrow oil and gas transport corridors (such as pipelines) to promote by their physical character coercive rule and militarization in the affected societies along the route - is directly linked to the societal effects produced by gas distribution pipelines.

Gazprom claims that it distributes prosperity to the Russian regions via gas pipelines, but when approached critically it also produces the means to strengthen its monopoly position in the Russian domestic gas market, as well as fortify its position in the eyes of the political elite, namely, Putin's regime, as the guarantor of central state power in the Russian regions. Naturally, the ability to control regions is not openly stated in Gazprom's strategies, rhetoric, or the Gazifikatsiya promo video, although the vast social programmes tied to it bear witness to the fact that the entire gas programme is a national endeavour linked to regional development and federal unity aims, especially in the coal industrydominated Russian Far East (Stolica na Onego 2012). This is not merely the commercial campaign of a company, as underscored by visual and discursive hints in the video.

Gas and its infrastructure - the geography of gas and the materialities it encompasses - are viewed as a tool for control on an international scale as well. Here, the narrative builds on the above-mentioned energy superpower discourse that has been intensively constructed in the Russian domestic arena during the 2000s. The topic of whether Russia is an 
energy superpower was hotly debated especially after the 2006 and 2009 gas disputes between Ukraine, Russia and the EU, but the issue was revived during the 2014 Ukrainian crisis. The way in which official Russia has talked about its energy as leverage is noteworthy: the assertive position of the early 2000s that Russia uses energy as a geopolitical resource, clearly stated in the Energy Strategy of Russia from 2003, was softened after 2008-9, when Russia articulated its energy policy aims towards the West. However, at the same time, the construction of the energy superpower discourse has intensified (especially during the 2014 crisis) with the Russian domestic audience, as clearly shown by Grib (2009). An energy superpower identity is built on tying together the subject nation and the energy rich nation. The video bases its argument on this discourse, as gas and gas infrastructure are defined as Russia's modern warfare. For example, military and geopolitical vocabulary and visions are used when discussing the gas infrastructure. Yamal gas resources are defined as "strategic" and the steel in the gas pipelines is referred to as having a "similar thickness to tanks". Moreover, when the personnel controlling the flow of gas in Gazprom's system are interviewed, a control screen focusing on Ukraine and Europe is shown in the background. The message is clear: Moscow and Gazprom's headquarters are defined as the centre of domestic and trans-boundary power. The director of the control room states that "any pipeline connection or compressor station can be controlled from here [while viewing the pipeline map of Europe] and we can intervene at any point" ( $v$ liuboi moment my mozhem vmeshatsya). This evokes the idea that Russia has the power to control others through gas, and individual Russian consumers have a duty and a privilege to be part of building this geopolitical power.

\section{MUTED ISSUES: WHAT IS NOT SHOWN OR DISCUSSED?}

Central to the use of power via discourses and practices are the issues and phenomena not discussed. Choosing to be silent about a topic deserving of mention is a power-vested tactic. Two important areas for the hydrocarbon businesses worldwide that are ignored in the video include the social inequalities and environmental problems produced along the commodity chain (Bridge 2011, pp. 318-20; Watts 2004a, p. 202; Watts 2004b, p. 59). For example, the indigenous people living in the gas producing region of Yamal receive no mention. Moreover, no ethnic groups other than Russians are shown in the video at all. The 
production region is presented like any other Russian region or territory, giving no hint about the ethnic diversity found there. Despite the fact that the Yamal is inhabited by the northern native Nenets, Hanti, Komi, and Selkup people - accounting for some 10 per cent of the population of the region - the video explains on two occasions that "no people live in this extreme environment". One explanation for this silence is the need to define gas culturally and ethnically as purely Russian, as argued earlier. The other reason could be the fact that by commenting on the ethnic history of the region, Gazprom and the state would be forced to comment on the societal effects of the hydrocarbon industries on the local communities, which would focus attention on issues such as land rights, welfare provision, and the economic equality of native people. Therefore, in the Gazifikatsiya governmentality, the geo is utilized also in a reverse manner as decisive geographical issues are excluded from the narrative.

Likewise, it is striking how the environmental question of gas production and transport is almost completely ignored in the video. Thus, nothing is said about the environmental consequences of gas production, locally or globally, except for the vague notion that gas is a goluboe toplivo ('baby-blue fuel'), hinting that gas is pure. There is no mention of the environmental consequences of gas transportation, which places a significant burden on the environment. The inefficiency of gas compressor stations is one reason why Gazprom is Gazprom's biggest client (Sutela 2012). Furthermore, the video does not comment on the energy inefficiency caused by a de facto pipeline monopoly of Gazprom. One central reason why oil companies have not been able to meet the associated petroleum gas utilization levels is because Gazprom blocks oil companies from feeding gas into the national pipeline system because it wants to avoid competition (e.g. Hulbak Røland 2010, p. 37).

Interestingly, another Gazprom promotional video intended for the international audience emphasizes that their operations in Vietnam, for example, are conducted according to the highest international environmental standards and follow the procedure of environmental impact assessments (Gazprom International 2012). Thus, being aware of this criticism of the upstream end, a question arises about whether companies such as Gazprom are trying to construct an image of a socially responsible player, both in their domestic upstream and downstream operations, while ignoring the environmental question that is internationally central for the hydrocarbon businesses. However, as stated earlier, this responsibility is ethnically discriminative because the indigenous people of the North are ignored in the video. The Russian private oil company Lukoil as well as the parastatal Gazprom have been criticized for neglecting their social and environmental responsibilities at the upstream end of the 
commodity chain (Greenpeace 2016). Yet they have both started to construct a self-image of a socially responsible company by using the material dimensions of energy as one medium in this construction (Rogers 2012, pp. 288-9; Rogers 2014, pp. 437-43).

My analysis reveals that the geo-governmentality practised by Gazifikatsiya derives its power from geographical knowledge and Soviet and post-Soviet imageries, and from the ability to do 'good' and 'bad'. The materialities of gas and gas infrastructures are used for both purposes. This bipartite energopower, a specific form of geo-governmentality, is invested with meaning by the existent materialities of hydrocarbons; the pipelines, for example, embody energy security and connectedness to the nation and its resource geography. The physical manifestation of Gazifikatsiya profoundly affects the construction of the social. Notions of Russia as a Territorial Superpower, Energy Superpower, and Ecological Great Power are all based on the centrality of this materiality. At the same time, this construction lumps together the material-specific and nationalistic image of energy with universal (neoliberal) binding goals, such as economic growth and modernization, and also with particular Russian values, including conservative gender roles. The materialities of gas thus feed into the national identity of Russians as citizens of an energy superpower. This power - projected via international gas pipelines and a military vocabulary - forms the core of the ability to do harm in the domestic arena as well: gas energy, infrastructure, and the gas industry are defined and viewed in a manner that underscores the submissive role of individuals and communities.

The production of truths, identity and power in this geogovernmentality take place via Foucault's dispositif, which includes institutional, physical and administrative mechanisms and knowledge structures. Several discourses, rooted in both the Soviet and post-Soviet nationalistic modernization ethos, are combined with the spatial and material characteristics of the gas industry to form a compelling narrative where institutional and administrative mechanisms - the Gazifikatsiya programme of a parastatal energy company - provide the frame. Furthermore, the five dimensions of the regimes of government defined by Legg (2005, pp. 147-9) are unfolded in my analysis: specific ways of thinking, the understanding of reality, the construction of certain subjectivities and refutation of others, strategic technologies of rule, and the values of a specific government. Moreover, the rationalities and practices of Gazifikatsiya geo-governmentality function in and combine several scales: the subject is tied to territories and the nation through gas, the subject is made responsible for the (bio)security of the population, and even the global is harnessed when legitimizing the heavy reliance on gas. 
Gazprom's Gazifikatsiya Rossii promotional video shows how the leadership of the company wants gas (as a substance and source of energy), the gas industry, and the Gazifikatsiya programme to be seen by the Russian people. I argue that this desire is also partly shared by the leadership of the country. The overt aim of the video is to show how many positive things gas can provide for Russians but, as I have stated above, there are subtle hints in the advertisement that gas has the ability to do harm as well.

The way Western observers understand harm is naturally influenced by the liberal and democratic understanding of what constitutes a negative societal development. Moreover, it can be argued that this Western, or at least European, understanding of energy as a societal force or actor is also biased. The fact that European consumers have become alienated from carbon energy - from the facts about how their mundane gas and gasoline are produced, where it comes from, the social and environmental consequences it causes, and how it actually keeps our mobile societies and democracies running - can be seen as a troubling issue. The Russian hydrocarbon culture takes a completely different approach to what energy means culturally, socially and economically. The Russian way of constructing an energy culture can also be seen as a more rational way of thinking about the energy dependence of society and the individual than the prevailing Western approach, which is more prone to dilute and push aside the fact that modern nations are deeply rooted in and dependent on fossil energy. Thus, hydrocarbon-culture construction efforts such as the Gazifikatsiya promotional video can serve as a sobering reminder for Western societies of what ultimately keeps our societies and economies running (Mitchell 2011).

Contrary to the Western understanding, the Russian people may choose to join the gas infrastructure and voluntarily remain under the patronage of the national monopoly and the federal centre. This positive understanding of patronage certainly has its roots in Soviet history (Collier 2011, pp. 238-9). According to this view, Gazifikatsiya simply mirrors some of the needs of the Russian population. In dialogue with this need, fostered by the present-day Soviet nostalgia among Russians, I will now take a more focused look at the hydrocarbon-culture governmentality by examining how Gazprom's programmes in the field of sports and youth reach beyond what is traditionally considered energy materiality, and how these materialities are utilized by those in power. 


\section{SPORT, 'GREATPOWERNESS', AND GAZPROM}

When approaching sport, the critical social sciences start with the assumption that it is as political as any other realm of international relations and cooperation (e.g. Sugden and Tomlinson 2002). Sport is political in at least three senses. First, doing sports and exercising is tied to the health of an individual as well as the population. Constructing sports facilities to promote sports and the health-oriented lifestyle it entails is therefore an essential social policy question in modern societies. Second, a healthy population links sport to soft-power issues, such as the national economy (individual as a worker), and to security and hardpower topics, such as military potential (individual as a soldier). This promotion of the ideal citizen as an able-bodied worker-soldier is related to the third way in which sport is political: it is about competition and, internationally, the pursuit of victory over other nations. Success in sport is not only seen as important for the self-esteem of an individual, but it can also function as one of the building blocks of national or ethnic identity. Faring well in global competition has long been understood as crucial to promoting a positive national image in the eyes of the international community (e.g. Koch 2013; Smith and Porter 2004).

Sport was an essential part of the Cold War rivalry between the capitalist and socialist world, led by the United States and the Soviet Union. In the Soviet Union, it was utilized to persuade global audiences that the socialist economic and societal model was better than capitalism. Significant investments were therefore made in sports training and coaching, and also in sport infrastructures and facilities of all kinds (e.g. Edelman 1993; Peppard and Riordan 1993). Indeed, many Russians today are nostalgic for the perceived success of the Soviet state in socio-political and cultural realms, including sports (Lee 2011; Mankoff 2009). In the context of the recent surge in Russia's Great Power ambitions, Russians continue to emphasize sports success in global arenas as one supposedly objective indicator of 'derzhava' or 'Greatpowerness' (Jokisipilä 2011). For example, organizing and doing well at the 2014 Sochi Olympic Games was widely framed by the media and the state as important for the self-esteem of ordinary Russians, which Putin's regime strategically leveraged as a tool to promote national pride (Persson and Petersson 2014).

In Sochi, as well as in nearly all Russian regions, major state-owned or dominated corporations have been obliged and are prepared to sponsor sport infrastructure construction and the communal infrastructures needed to operate these premises (e.g. Müller 2011; Trubina 2014). Gazprom and 
the state-dominated oil company Rosneft were accorded the widest responsibilities in this field. The Sochi games thus illustrated a wider triangle uniting Russian sports, energy and Great Power status - with accumulated energy wealth not only being invested in the military apparatus to expand Russia's 'Greatpowerness' (Baev 2008), but also poured into sports and the related infrastructure.

Gazprom's extensive social responsibility programmes, namely 'Gazprom - for Children' (Gazprom 2015d) and 'Sponsoring Sports' (Gazprom 2015h), are part of the company's general strategy and operations. The largest share of Gazprom's sport sponsorship goes directly to ice hockey and soccer clubs and associations. For example, from 2008 to 2014, the Director-General of Gazprom Export, Alexander Medvedev, was the President of the Russia's Continental Hockey League (KHL), which is only economically viable due to generous funding from the national energy giants Gazprom and Rosneft. Seen by some observers as a 'soft' geopolitical tool of President Putin's Great Power agenda, the KHL has expanded beyond the borders of Russia to purchase and include teams from regional neighbours, including Serbia, Slovakia, Latvia, Finland and Kazakhstan (Jokisipilä 2011). In ice hockey, the link between the state and the energy sector is the strongest, yet Gazprom is also a major sponsor of European soccer. Internationally, Gazprom's sport sponsorship is primarily justified on the economic grounds of promoting visibility in its main market area, but the soft power aims of the Russian state also play a role.

Domestically, sponsorship of and investments in sports are overrepresented in both the upstream (energy producing) and downstream regions (those with little or no gas coverage) of the gas commodity chain. The highly visible and spatially extensive social responsibility projects in the sphere of sports are thus treated as one of Gazprom's tools for promoting the national gas programme in these key areas. Sport is an ideal means to do so, as it has so many positive connotations for Russians, both individually and on a broader socio-cultural level. By amalgamating the gas programme with sports-related social responsibility, Gazprom can cultivate an image of 'doing good' for society, while simultaneously promoting the less benign objectives of the Russian state and the present regime in biopolitical and energopower terms - namely, emphasizing the importance of a physically and mentally healthy population that suits the needs of the Russian economy and military. The pact of energy and sports advances a conservatively defined communality (communitarianism) via sports halls and clubs, and fosters a national identity based on the idea of Russia as a Great Power. For example, as part of Gazprom's 'Sponsoring Sports' programme, and in addition to more than a thousand 
sports infrastructure projects carried out since the mid-2000s in the form of ice hockey halls, tennis courts, sports halls, and various athletics fields, the company promotes a Russia-wide programme of physical training and sports called 'Ready for Work and Military Defence' (Gotov $k$ trudu $i$ oborone), which is led by the Ministry of Sports (Gazprom 2015f; Ministerstvo Sporta RF 2015). Gazprom sponsors this national sport and military preparedness programme, and has also started to require its employees to take the battery of physical tests, including short and long distance running, swimming, skiing, pull-ups and long jump, as well as (artificial) grenade throwing and shooting with a rifle.

Another example accentuating the biopolitical objectives (for example, that physically and mentally fit bodies serve economic but also military and other patriotic ends) is visible in the social responsibility programme 'Gazprom - for Children'. This programme is dominated by local-level sports sponsorship and infrastructure construction projects carried out by Gazprom and its regional subsidiaries, but it also includes a patriotic song contest called 'Flare of Hope' (Fakel Nadezhdy) (Gazprom 2015g). If the sports projects aim at physically fit patriotic citizens, this project aims specifically at producing a mentally strong and unified youth that shares the government's patriotic goals to benefit the country economically and militarily. A quote from the head of the Culture and Arts Department of the City of Orenburg on Gazprom's website advertising the song contest makes the connection clear: "I am sure these children will grow up to be good, wise people who will make this country richer and more powerful. Thank you, Gazprom, for your loyalty towards traditions!" (Gazprom 2015c). Here, traditions can be understood as a reference to traditions of the Russian state - with its emphasis on Great Power status, loyalty to authoritarian rule and its leader, and the obsequious citizen as a patriotic ideal.

\section{CASE: RUSSIAN GAS AND SPORTS FIELDS DISPLACING LOCAL RENEWABLES IN KARELIA}

Gazprom's numerous projects and programmes are firmly tied to the countrywide gas programme Gazifikatsiya Rossii. On the grounds of enhancing energy security, promoting economic growth, regional investment, and environmental protection, Gazprom and the Russian government assert the importance of extending the country's gas distribution network to its peripheries. The Republic of Karelia, which borders on Finland and the EU, is one such peripheral region. Exemplifying the 
themes discussed so far, the remainder of this chapter focuses on a case study of Gazprom's projects in Karelia.

The Gazifikatsiya programme has been running since the mid-2000s, but the most intensive phase started in 2010-11 (Gazprom 2012), including the republic of Karelia. One specific feature of Gazifikatsiya is that all gas pipeline projects and gas-powered plants built by Gazprom have a social infrastructure component. In the case of Karelia, this has been significant: in its Ladoga district, a deal was struck in 2012 to invest six billion roubles in gas infrastructure, while at the same time earmarking two billion roubles for social infrastructure (Peterburgregiongaz 2012). These figures may be staggering, but Gazprom, along with other major Russian enterprises, is in fact legally obliged by the government to carry out certain philanthropic activities. As Gazprom cannot evade these obligations, its executives prioritize acts of charity that can maximize gains for both the company and its backers in the state. As discussed above, Gazprom-branded sports halls and athletics fields have topped the list of preferred projects.

In Karelia, settlements predominantly import their electricity from outside the region and heat supplies have traditionally come from oil or coal, even though the region is rich in wood resources and has a long history of local forestry. As a whole, the Republic of Karelia imports 70 per cent of its energy, indicating that the forest industry, in supplying the remaining 30 per cent, is responsible for a significant share of the region's local energy. In fact, Karelia made several plans and agreements from 2001 to 2003 to decrease energy import dependency by constructing new power plants running on woodchips and peat (Pravitelstvo RK 2001). But by 2004-5, Gazprom started negotiations to expand its gas distribution pipelines in Karelia and to construct gas-burning heat plants. This resulted in an agreement between Gazprom and the government of the Republic of Karelia in 2006 on 'Gasification of the Republic', with Gazprom launching pipeline and heat plant construction in 2007 amounting to 490 million roubles through 2010.

In 2011, Gazprom invested an additional 180 million roubles in the Karelian heat and power sector (Peterburgregiongaz 2012). All these investments laid the foundation for the 2012 Ladoga deal mentioned above, in which Gazprom would undertake the gasification of the Northern Ladoga territories of Karelia at the cost of six billion roubles for gas infrastructure (pipelines and power and heat plants), plus two billion roubles for social infrastructure - predominantly indexed for constructing sport facilities (Stolica na Onego 2012). However, the gas investment programme was not sold to Karelian politicians and authorities simply on the basis of economic and energy security arguments, but 
with promises of social infrastructure construction in the form of several sports halls and fields. Such projects offered links to 'positive' national objectives, making gas look more appealing than local energy sources and energy self-sufficiency. In the Ladoga region, these social sports projects consumed one quarter of all money invested in Karelia as a whole. By prioritizing these sport facilities over other potential social infrastructure projects, Gazprom's initiatives have helped to further entrench the nationalist valorization of sports as united with Great Power aspirations, while also advancing the state's biopolitical and energopolitical objectives.

While these national biopolitical objectives are certainly pivotal for Gazprom's programmes to gain acceptance and support inside Putin's regime, the local practices evolving in and around such programmes are implicated in a more nuanced and multifaceted set of power relations. During the 1990s, before the era of state corporations' social responsibility programmes and sport facility sponsorship in the Russian regions, Karelia's municipal and regional leaders preferred visible infrastructure construction and renewal projects, such as paving of streets, building pedestrian streets and shorelines, and statues and fountains, over invisible, yet more vital renewal projects, such as enhancement of drinking water safety by investing in obsolete water treatment plants and the deteriorating drinking water and sewage pipeline systems (Tynkkynen 2001). Sports facilities have increasingly become one such visible project preferred by regional leadership.

As highly visible sites in urban centres impacting and 'traversing' the everyday life of many people, Gazprom-sponsored sport facilities play a multidimensional role in allowing localities to reassert power and control within national hierarchies. For example, one strategy for local and regional politicians in Karelia to remain in positions of power involves promoting the objectives set by the nation's corporate champions, like Gazprom, so that central officials in the Kremlin see them as reliable and submissive technocrats. However, sports halls and athletic fields that structure urban space are also a way to legitimize chosen policies in the eyes of the local inhabitants, and to show people that the local elite is aligned with the national power and its supra-local objectives. Furthermore, sport infrastructure construction is a highly profitable business with large possibilities to divert money to the regional leadership's entourage, and is thus a means to build and fortify allegiances and local centres of power. Indeed, across Russia and the post-Soviet space, state-sponsored sport facility construction business is not only lucrative; it also enables corruption better than other businesses (Müller 2011; Trubina 2014). Therefore, this 'potential' for lubricating local power 
machines is possibly one central motivation for local and regional politicians and authorities to promote social responsibility programmes set by the centre that include building sport infrastructure.

As seen in the Karelia case, Gazprom's decision to emphasize sports facilities that are highly visible 'commercial' objects, raises the question of whether these projects are appropriately categorized as social charity. This in turn raises the related question of whether such projects are more closely related to the company's marketing campaign - aimed at highlighting the company as a socially responsible actor and 'whitewashing' its image - than engaging in philanthropic activities that would promote the well-being of the populace in a more substantive fashion, such as by developing social housing, hospitals, schools, etc. By claiming to be socially responsible via the provision of sport facilities, the state giant signals in a markedly neoliberal biopolitical way that 'social responsibility' entails promoting fit citizens who might benefit the society, its economy, and military might, in other words, its Great Power ambitions through self-help and exercise. The state and the company cooperate to provide a setting that enhances communitarianism via local sport institutions, but the individual and communities are ultimately made responsible for accomplishing the biopolitical objectives set by the state.

Without doubt, Gazprom's Gazifikatsiya campaign produces positive impacts as it expands to new areas, increasing the reliability of energy deliveries in comparison to peripheral settlements being dependent on imported oil and coal. At the same time, connecting new areas to centrally-governed pipelines makes these territories and regional actors much more dependent on Gazprom and the state. As scholars have pointed out, pipes matter (Bridge 2009, 2011; Collier 2011) - especially in the post-Soviet context. Not only do gas pipelines construct dependencies and interdependencies between Russia and its consumers (mainly in Europe), but they are also key to forming and sustaining structures of power inside Russia. Gazprom-funded sports infrastructure thus acts like an extension of gas infrastructure, an 'epiphyte' both luring and compelling towns and settlements to join the nation-building project, Gazifikatsiya Rossii. It is here that the national energy, cultural, and military 'Great Power' narratives converge.

\section{SPORT, ENERGOPOWER AND CORPORATE GOVERNMENTALITY}

Discursive (biopolitical) and coercive (anatomopolitical) governmentality come together in the energopower practised by Gazprom and the Russian 
state. The amalgamation of energy and sports makes it possible to practise discursive and coercive power cunningly, as the 'presence' of the state is made concrete through both gas pipelines and visible and spatially extensive sport facilities. Gazprom's all-Russian gas programme and its practices on the local level, as exemplified via the Karelia case study, may be a form of corporate whitewashing, but it also advances the Great Power ambitions of Putin's regime in the name of social 'responsibility'. Parastatal Gazprom has managed to construct a truth in which it has cast sports-related investments as a form of 'responsible' social provisioning and infrastructure development. However, genuine philanthropy in the form of investments in basic social infrastructure and communal amenities such as schools and hospitals, or pure drinking water and non-toxic sewage, or assistance of disabled groups and poverty relief, does not take place.

Thus, the position of major energy corporations in post-socialist Russia as formulators of what is worth knowing and what is the truth, is exceptionally strong. This is partly due to the fact that Russian people demand and expect patronage from the state and its corporations, as they used to do during the Soviet era. For the most part, the population, local and regional stakeholders find themselves agreeing with the hegemonic discourse that the state defines what is good for the people and the regions. However, as a Foucauldian theoretical approach suggests, power produces counter-power that both opposes more hegemonic claims to truth and also adapts to its objectives by changing it slightly and adding contextual nuances and peculiarities to it (e.g. Tynkkynen 2009a). In the Russian regions, therefore, we find that the national patriotic agenda is utilized locally not just to maintain power, but also to challenge it - and Russians actively demand concessions from the state. For example, in the Perm region bordering to the Urals, where Gazifikatsiya has been carried out far longer than in Karelia, the municipalities, the local power and heat providers, as well as private households have come to expect inexpensive delivery of gas as a civil right. And as Gazprom has steadily raised gas prices, the communal companies and households have refused to pay. In the Perm region alone, the municipalities had in 2013 accrued a debt to Gazprom of approximately two billion roubles. Gazprom may thus 'deliver' state power along with gas pipelines and its sporty 'epiphytes' as it enters new regions like Karelia, but at the same time it is aware of the oppositional potential of communities to both counter and redeploy the hegemonic discourse of state patronage.

However, Gazprom's sports-orientated social programme ultimately aims to responsibilize individuals to ensure the well-being of both self and nation, its economy and military might. Its unique form of corporate 
governmentality can thus be defined as a matrimony of the energy superpower ideal and military Great Power identity that are constructed with the help of sports metaphors, values and infrastructures. Sport is utilized to steer energy policies on the local and regional level, as was clearly shown in the Karelian case when the gas programme pushed local bioenergy and energy self-sufficiency goals off the regional agenda. The compelling nationalist narratives manifested in the triangle uniting Russian sport, energy and Great Power status are therefore just as important as the mundane energy security objectives used to persuade Karelian leadership and communities to join Gazifikatsiya Rossii. 